\title{
The Relationship of Fetuin-A, Omentin-1, and Chemerin with Left Ventricular Ejection Fraction in Heart Failure
}

\author{
Sefa Erdi Ömür, İdris Buğra Çerik', Gülaçan Tekin ${ }^{1}$ \\ Department of Cardiology, Tokat State Hospital, Tokat, ' Sivas Cumhuriyet Universty, Sivas, Turkey \\ ORCID: \\ Sefa Erdi Ömür: https://orcid.org/0000-0002-6209-1732 \\ İdris Buğra Çerik: https://orcid.org/0000-0003-1419-3950 \\ Gülaçan Tekin: https://orcid.org/0000-0002-1355-9298
}

\section{Abstract}

Background: Heart failure (HF) is a clinical syndrome in which the heart cannot pump enough blood for the needs of the human body in terms of life functions. Some biochemical diagnostic tests as well as echocardiography play a role in the early diagnosis of this syndrome. The complex pathophysiology of HF suggests that many other markers may be useful in diagnosis and follow-up. Aim: After many recent studies, it has been suggested that adipokines fetuin-A, omentin-1, and chemerin may be suitable biomarkers for the diagnosis of HF. Our main aim in this study is to determine the relationship between fetuin-A, omentin-1, and chemerin levels with HF clinical classification. Methods: The patients admitted to the cardiology service with symptomatic HF with HF with preserved ejection fraction $(\mathrm{HF}-\mathrm{pEF}, n=62)$, $\mathrm{HF}$ with reduced $\mathrm{EF}(\mathrm{HF}-\mathrm{rEF}, \mathrm{n}=61)$ and $\mathrm{HF}$ with mid-range $\mathrm{EF}(\mathrm{HF}-\mathrm{mrEF}, n=63)$ were included in the study. A total of 246 participants were evaluated by taking the control group $(n=60)$ for comparison. The main characteristics of all groups were recorded, and serum levels of fetuin-A, omentin-1, and chemerin were evaluated. Results: When compared with the control group, there was a significant difference for fetuin-A with the HF-rEF group (452.3 [441.4-528.9]; 555.3 [453.7-615.6] $P<0.001$, respectively). When evaluating for omentin-1, there was a significant difference between the control group and HF-rEF. However, there was no significant difference for chemerin between the HF groups and the control group. Significant cutoff value for fetuin-A was found to be 485 in receiver operating characteristic analysis (area under curve: 0.74 sens: 0.72 (95\% confidence interval [CI]: 0.57-0.82), spec: 0.69 (95\% CI: $0.59-0.83), P<0.001)$. Conclusion: Serum fetuin-A levels were found to be high in the HF-mrEF and HF-rEF groups from the HF groups and can be used in the diagnosis of the HF-rEF group.

Keywords: Adipokines, chemerin, fetuin-A, heart failure, omentin-1

\section{INTRODUCTION}

Heart failure (HF) is a complex syndrome, which causes the heart's inability to send oxygen to the tissues to meet its metabolic needs, or which proceeds with high filling pressures due to structural anomalies, insufficient cardiac filling, and neurohormonal activation, consequentially where symptoms such as shortness of breath, rapid fatigue, and clinical signs such as peripheral edema occur. ${ }^{[1]}$ Despite well-regulated therapeutic treatments, HF remains a leading cause of death worldwide. ${ }^{[2]}$ Therefore, early diagnosis and treatment of HF is important in reducing the mortality and morbidity rates of people with this disease. ${ }^{[3]}$

Received: 14-08-2021 Revised: 05-09-2021 Accepted: 10-09-2021

Published Online: 29-01-2022

\begin{tabular}{|l|l|}
\hline \multicolumn{3}{|c|}{ Access this article online } \\
\hline Quick Response Code: & Website: \\
& \\
http://www.ijcva.com
\end{tabular}

Adipose tissue, which was originally thought to be only a depot or free fatty acid source for triglycerides, is now considered a very important part of the energy mechanism with many enzymes, growth factors, cytokines, and hormones it secretes. ${ }^{[4]}$ It is known that mature adipocytes act as an endocrine organ in adipose tissue and play a role in organ communication through the mediators they secrete. ${ }^{[5]}$ These mediators, which are actively secreted from white adipose tissue, are called adipokines. The mediators play a role in many metabolic and

Address for correspondence: Dr. Sefa Erdi Ömür, Department of Cardiology, Tokat State Hospital, Tokat, Turkey. E-mail: sefaerdi61@gmail.com

This is an open access journal, and articles are distributed under the terms of the Creative Commons Attribution-NonCommercial-ShareAlike 4.0 License, which allows others to remix, tweak, and build upon the work non-commercially, as long as appropriate credit is given and the new creations are licensed under the identical terms.

For reprints contact: WKHLRPMedknow_reprints@wolterskluwer.com

How to cite this article: Ömür SE, Çerik İB, Tekin G. The relationship of fetuin-A, omentin-1, and chemerin with left ventricular ejection fraction in heart failure. Int J Cardiovasc Acad 2021;7:111-8. 
physiological events of the body such as coagulation, nutrition, vascular remodelling, appetite, energy balance, blood pressure regulation, insulin and glucose metabolism, lipid metabolism, and inflammation. ${ }^{[6]}$

It is known that changes in the amount of adipokines secreted by adipose tissue play a role in the pathogenesis of diseases. The relationship between adipokines and obesity and obesity-related pathological processes was initially defined. ${ }^{[7]}$ It has been observed that type 2 diabetes and cardiovascular diseases may occur as a result of systemic inflammation, especially in visceral lipoidosis. Increased cytokine levels as a result of this inflammation cause myocyte loss and apoptosis in vascular endothelial cells, leading to left ventricular (LV) dilatation and hence HF. ${ }^{[8]}$ Studies have also revealed the role of adipokines in cardiovascular diseases. ${ }^{[9]}$ It has been suggested that fetuin-A, omentin-1, and chemerin might be suitable biomarkers for HF. ${ }^{[10,11]}$ However, how these biomarkers change according to HF subgroups has not yet been defined. The study was designed based on the evidence gap, and its main purpose is to evaluate the relationship between fetuin-A, omentin-1, and chemerin with clinical classification in HF groups.

\section{Methods}

The research is a case-controlled cross-sectional study consisting of experimental and control groups. The research was conducted in a manner consisting of the patients hospitalized with symptomatic HF at a local university hospital between March 2018 and March 2019 and the volunteers without a diagnosis of HF forming the control group. Approval was obtained from the ethics committee of the Sivas Cumhuriyet University-date: February 6, 2018, number: 2018-02/06-where our institution was conducted, and informed consent was obtained from the participants or their guardians.

The study complies with the principles set out in the declaration of Helsinki and has been approved by the local university hospital ethics committee.

Approximately 60 patients were planned to be included in the study for each HF group. These groups were completed according to the diagnoses of the consecutive patients. The control group was planned to consist of 60 patients without HF. The patient group consisted of 186 patients with a diagnosis of HF (62 preserved ejection fractioned HF [HF-pEF], 61 reduced ejection fraction HF [HF-rEF], 63 midrange ejection fraction HF [HF-mrEF]). The control group consisted of 60 age-matched patients without HF. The patients included in the patient group of the study were selected from those with chronic HF and those who presented with acute exacerbation of HF. The drugs used by the patients regularly in the last month were noted. Echocardiography was performed with Vivid 3 echocardiography device (General Electrics, Vivid 3 echocardiography, Milwaukee, WI, USA) in the Echocardiography Laboratory of the local university hospital. All echocardiographic evaluations were performed separately by two experienced cardiologists who were blind to the study design, in accordance with the recommendations of the American Echocardiography Association. ${ }^{[12]}$ The identity of the patient, blood pressure during the examination, and electrocardiography (ECG) recording with clear $\mathrm{P}$ and $\mathrm{R}$ waves were observed on the echocardiography device screen. The patient was placed in the left lateral decubitus position for parasternal and apical examinations. For parasternal imaging, the transducer was placed in the third or fourth intercostal space and long- or short-axis views of the heart were obtained. For apical examination, the transducer was placed where the apical beat was felt, and four and five chambers of the heart were imaged. LV end-diastolic diameter were measured at the end of diastole and left atrial size at the end of systole from parasternal and apical viewing windows. Myocardial thickness used for LV hypertrophy was calculated from the short axis epicardial and cavity areas. Modified Simpson method was used for LV ejection fraction (EF).

The age, gender, and medical history of the patients included in the study (diabetes mellitus, hypertension, hyperlipidaemia, comorbidities, smoking status, and medications) were questioned, and their body mass index (BMI) was calculated. Blood samples of the patients were taken within the first $12 \mathrm{~h}$ after admission with decompensation. For blood sampling, the patients were taken after $10 \mathrm{~h}$ of fasting and nonsmoking. Subsequently, venous blood samples were taken from the patients after 15 min of rest in a sitting position for biochemical examinations. After obtaining detailed consent from the control group and patients diagnosed with HF, $5 \mathrm{ml}$ venous blood samples were taken into a gel biochemistry tube (BD Vacutainer). Lateron, serums separated from venous blood samples by centrifugation for $15 \mathrm{~min}$ at $15000 \mathrm{rpm}$ were then stored in Eppendorf tubes $(2 \mathrm{ml})$ at $-20^{\circ} \mathrm{C}$. During the analysis, after the serums are left to dissolve at room temperature, fetuin-A, omentin-1, chemerin, and NT-proBNP values were calculated by using Elabscience brand manual enzyme-linked immunosorbent assay kits and enzyme-linked binding protein assay sandwich method. Five ml full blood was taken into a gel biochemistry tube (BD Vacutainer) for other biochemical examinations of the patients, and $2 \mathrm{ml}$ full blood was taken into a ethylenediaminetetraacetic acid tube for hemogram analysis. The samples for biochemical examinations were studied on Beckman Coulter AU5800 device, and those for hemogram were studied in DIRUI BF 6500 device.

The inclusion criteria were that the patients be in any of the HF groups and be symptomatic. For the diagnosis of HF-rEF in the patient group; it was requested that $\mathrm{EF}<40$ and that patients have symptoms or signs of HF. For the diagnosis of $\mathrm{HF}-\mathrm{mrEF}$, it was requested that EF value be between 40 and 49 , NT-proBNP $\geq 125 \mathrm{pg} / \mathrm{ml}$ the left atrial dilation (left atrial volume index of $>34 \mathrm{ml} / \mathrm{m}^{2}$ ) $/ \mathrm{LV}$ hypertrophy (LV mass index male $\geq 115 \mathrm{~g} / \mathrm{m}^{2}$ female $\geq 95 \mathrm{~g} / \mathrm{m}^{2}$ ) and having HF symptoms and signs, For the diagnosis of HF-pEF, it was requested that $\mathrm{EF} \geq 50$, NT-proBNP $\geq 125 \mathrm{pg} / \mathrm{ml}$ the left atrial dilation (left atrial volume index of $>34 \mathrm{ml} / \mathrm{m}^{2}$ ) $/ \mathrm{LV}$ hypertrophy (LV mass 
index male $\geq 115 \mathrm{~g} / \mathrm{m}^{2}$ female $\geq 95 \mathrm{~g} / \mathrm{m}^{2}$ ) having HF symptoms and signs. ${ }^{[13]}$ All of the patients included in the control group were selected from those who admitted to the local university hospital and did not have HF.

The patients with active infection, malignancy, coagulation disorder, under 18 years of age, storage diseases (glycogen, lipid, lysosomal, etc.), acute kidney disease, end-stage renal failure, severe anemia, and recent acute coronary syndrome (first 6 months) were not included in the study.

The data obtained from the study were evaluated with the SPSS (22.0; SPSS Inc., Armonk, NY, USA) program. The categorical variables were expressed as number and percentage $(\mathrm{n} \%)$, whereas continuous variables were expressed as mean \pm standard deviationor median, interquartile range according to the distribution of the data. The normality of the data was measured with the Kolmogorov-Smirnov test. If the data met the parametric conditions (data are obtained by interval, ratio scale, and normal distribution), they were analyzed with an independent sample $t$-test for two independent groups and the F test (ANOVA) for more than two independent groups. While ANOVA is used for comparisons with more than two independent groups, the Tukey test was used for those who provided the homogeneity assumption to determine which group was different from the others, Games-Howell test was used for those who did not provide the assumption of homogeneity. Mann Whitney $U$ was used for two independent groups when it did not satisfy any or all of the parametric assumptions. The Chi-square test was used to evaluate the categorically obtained data. Receiver operating characteristic (ROC) graph was obtained by applying ROC analysis to evaluate the diagnostic test performance of fetuin-A diagnostic test in determining the HF-rEF status. Spearmen correlation analysis was used for the correlation analysis of fetuin-A and NT-proBN $P$ values. For statistical significance, the rate was taken as $P \leq 0.05$ in the tests.

\section{Ethical statement}

Approval was obtained from the ethics committee of the Sivas Cumhuriyet University -date: 06.02.2018, number: 2018-02/06where our institution was conducted, and informed consent was obtained from the participants or their guardians.

\section{RESULTS}

The basic characteristics, age, BMI, comorbidities, used medications, ECG rhythm and smoking habits of the patients included in the study and those of the control group were noted. The basic characteristics of the patients are detailed in Table 1 . Sixty patients ( 28 women and 32 men, mean age $67.35 \pm 6.65$ years) in the control group, 186 patients in the HF group ( 62 patients HF-pEF ( 37 women and 25 men mean age: $71.53 \pm 7.05), 61$ patients HF-rEF ( 25 females and 36 males mean age: $67.62 \pm 9.89$ ), 63 patients HF-mrEF (32 females and 31 males mean age: $69.93 \pm 11.59)$ ] were evaluated. The proportion of female patients was significantly higher in the HFpEF patient group compared to the other patient groups and the control group $(P<0.01)$. The BMIs of the patients and control group were calculated separately and it was detected that $30.21 \pm 6.20 \mathrm{~kg} / \mathrm{m}^{2}$ in HF-rEF, $32.72 \pm 8.08 \mathrm{~kg} / \mathrm{m}^{2}$ in HF-mrEF, $33.46 \pm 7.05 \mathrm{~kg} / \mathrm{m}^{2}$ in HF-pEF, and $29.27 \pm 4.33 \mathrm{~kg} / \mathrm{m}^{2}$ in the control group. BMI was found to be higher in HFpEF compared to other patient groups and control group and this was significant $(P<0.01)$. While $52(85.24 \%)$ patients had coronary artery disease (CAD) in the HF-rEF patient group, CAD was present at $50(79.36 \%)$ patients in HF-mrEF, at $37(59.67 \%)$ patients in HF-pEF and at $32(53.33 \%)$ patients in the control group. CAD was found to be significantly higher in the HF-rEF and HF-mrEF patient group compared to the control group $(P<0.001)$, but there was no significant difference between the HF-pEF patient group and the control group. Among the patient groups, especially in HF-rEF and HF-mrEF, the rate of beta-blocker and ACE/ ARB use was found to be above $90 \%$ [Table 1].

The functional capacities of the patients also varied between the groups [Table 2]. Functional capacities of the patients were determined according to New York Heart Association (NYHA) evaluation.

There was no significant difference in many biochemical parameters in the patient and control groups. However, it was found that the values as glucose (HF-rEF $117 \mathrm{mg} / \mathrm{dL}$ (90-144 mg/dL), HF-mrEF $112 \mathrm{mg} / \mathrm{dL}(89-130 \mathrm{mg} / \mathrm{dL}), \mathrm{HF}-\mathrm{pEF}$ $109 \mathrm{mg} / \mathrm{dL}$ (96-132 mg/dL), control $95 \mathrm{mg} / \mathrm{dL}$ (90-112 mg/dL), p: 0.008 ), creatinine (HF-rEF $1.19 \pm 0.36 \mathrm{mg} / \mathrm{dL}, \mathrm{HF}-\mathrm{mrEF}$ $1.13 \pm 0.51 \mathrm{mg} / \mathrm{dL}$, HF-pEF $1.27 \pm 0.57 \mathrm{mg} / \mathrm{dL}$, control $0.83 \pm 0.18 \mathrm{mg} / \mathrm{dL}, P<0.001)$ and BUN (HF-rEF $28.04 \pm 14.29 \mathrm{mg} / \mathrm{dL}, \mathrm{HF}-\mathrm{mrEF} 27.83 \pm 13.46 \mathrm{mg} / \mathrm{dL}, \mathrm{HF}-\mathrm{pEF}$ $33.34 \pm 15.10 \mathrm{mg} / \mathrm{dL}$, control $15.96 \pm 5.41 \mathrm{mg} / \mathrm{dL}, P<0.001)$ were higher in the patient groups compared to the control group [Table 3]. LDL values (HF-rEF $89.83 \pm 38.71 \mathrm{mg} / \mathrm{dL}$, HF-mrEF $87.25 \pm 37.87 \mathrm{mg} / \mathrm{dL}$, HF-pEF $91.12 \pm 34.50 \mathrm{mg} / \mathrm{dL}$, control $108.63 \pm 35.23 \mathrm{mg} / \mathrm{dL}, \mathrm{p}: 0.006$ ) were found to be higher in the control group compared to the patient groups [Table 3]. While the CRP value shown in Table 3 (HF-rEF $14.35 \pm 14.87 \mathrm{mg} / \mathrm{L}$, HF-mrEF $10.93 \pm 13.73 \mathrm{mg} / \mathrm{L}$, HF-pEF $17.49 \pm 22.15 \mathrm{mg} / \mathrm{L}$, control $6.00 \pm 6.44 \mathrm{mg} / \mathrm{L}, P<0.001$ ) was similar in the patient groups, it was found significantly higher in HF-rEF and HF-pEF compared to the control group.

\section{Fetuın-A}

Fetuin-A value [HF-rEF $555.3 \mathrm{ng} / \mathrm{mL}$ (453.7-615.6 ng/mL), HF-mrEF $443.2 \mathrm{ng} / \mathrm{mL}(436.2-453.2 \mathrm{ng} / \mathrm{mL})$, HF-pEF $512.7 \mathrm{ng} / \mathrm{mL}$ (452.6-571.6 ng/mL), control $452.3 \mathrm{ng} / \mathrm{mL}$ (441.4-528.9 ng/mL), $P<0.001]$ HF-rEF and HF-pEF was found to be significantly higher in patient groups than the control group [Table 3]. However, no significant difference was found in HF-mrEF compared to the control group [Table 3]. When all HF groups were evaluated together and compared with the control group, it was observed that only fetuin-A ( $P=0.031)$ made a significant difference, but there was no significant difference in omentin- 1 and chemerin (p: 0.879, p: 0.487 , respectively). 


\begin{tabular}{|c|c|c|c|c|c|}
\hline Variables & HF-rEF $(n=61)$ & HF-mrEF $(n=63)$ & HF-pEF $(n=62)$ & Control $(n=60)$ & $P$ \\
\hline Age, mean \pm SD & $67.62 \pm 9.89$ & $69.93 \pm 11.59$ & $71.53 \pm 11.65$ & $67.35 \pm 6.65$ & 0.29 \\
\hline $\mathrm{BMI}$, mean $\pm \mathrm{SD}$ & $30.21 \pm 6.20^{\mathrm{a}}$ & $32.72 \pm 8.08^{\mathrm{a}}$ & $33.46 \pm 7.05^{\mathrm{b}}$ & $29.27 \pm 4.33^{\mathrm{a}}$ & 0.01 \\
\hline Gender (female), $n(\%)$ & $25(41)^{\mathrm{a}}$ & $32(50.8)^{\mathrm{a}, \mathrm{b}}$ & $37(59.7)^{\mathrm{b}}$ & $28(46.7)^{\mathrm{a}}$ & $<0.01$ \\
\hline Diabetes mellitus, $n(\%)$ & $33(54.09)$ & $33(47.61)$ & $30(48.38)$ & $22(36.66)$ & 0.18 \\
\hline Hypertension, $n(\%)$ & $37(60.65)$ & $41(65.07)$ & $46(74.19)$ & $35(58.33)$ & 0.293 \\
\hline COPD, $n(\%)$ & $19(31.14)$ & $14(22.22)$ & $23(37.09)$ & - & $<0.01$ \\
\hline Asthma, $n(\%)$ & $1(1.69)$ & $4(6.34)$ & $4(6.45)$ & - & 0.131 \\
\hline $\mathrm{CAD}, n(\%)$ & $52(85.24)^{\mathrm{a}}$ & $50(79.36)^{\mathrm{a}}$ & $37(59.67)^{\mathrm{b}}$ & $32(53.33)^{\mathrm{b}}$ & $<0.01$ \\
\hline Atrial fibrillation, $n(\%)$ & $25(40.98)$ & $22(34.92)$ & $26(41.93)$ & $1(1.66)$ & $<0.01$ \\
\hline Pace rhythm, $n(\%)$ & $3(4.91)$ & $1(1.58)$ & $1(1.61)$ & - & 0.274 \\
\hline $\mathrm{LBBB}, n(\%)$ & $10(16.39)$ & $5(7.93)$ & $2(3.22)$ & - & 0.02 \\
\hline Smoking, $n(\%)$ & $10(16.39)$ & $3(4.76)$ & $3(4.83)$ & $5(8.33)$ & 0.07 \\
\hline Furosemid dosage (mg), mean \pm SD & $93.77 \pm 46.69$ & $92.69 \pm 52.70$ & $118.70 \pm 50.68$ & - & $<0.01$ \\
\hline Digoxin, $n(\%)$ & $7(11.47)$ & $2(3.17)$ & $3(4.83)$ & - & 0.026 \\
\hline MRA, $n(\%)$ & $47(77.04)$ & $34(53.96)$ & $23(37.09)$ & - & $<0.01$ \\
\hline Ivabradin, $n(\%)$ & $7(11.47)$ & $4(6.34)$ & - & - & 0.004 \\
\hline $\mathrm{ACE} / \mathrm{ARB}, n(\%)$ & $56(91.80)$ & $55(87.30)$ & $42(67.74)$ & $16(26.66)$ & $<0.01$ \\
\hline Beta-blocker, $n(\%)$ & $60(98.369)$ & $57(90.47)$ & $46(74.19)$ & $1(1.66)$ & $<0.01$ \\
\hline Antiaggregan, $n(\%)$ & $40(65.57)$ & $40(63.49)$ & $28(45.16)$ & $24(40)$ & 0.004 \\
\hline Warfarin, $n(\%)$ & $4(6.65)$ & $5(7.93)$ & $9(14.51)$ & $1(1.66)$ & 0.065 \\
\hline NOAC, $n(\%)$ & $20(32.78)$ & $7(11.11)$ & $11(17.74)$ & - & $<0.01$ \\
\hline Ranolazine, $n(\%)$ & - & $4(6.34)$ & $1(1.61)$ & - & 0.037 \\
\hline
\end{tabular}

Table 2: Evaluation of New York Heart Association classification of heart failure patient groups

\begin{tabular}{|c|c|c|c|c|c|}
\hline & HF-rEF $(n=61), n(\%)$ & HF-mrEF ( $n=63), n(\%)$ & HF-pEF $(n=62), n(\%)$ & Control $(n=60), n(\%)$ & Total \\
\hline NYHA 1 & - & - & - & $60(100)$ & $60(24.4)$ \\
\hline NYHA 2 & $48(78.7)$ & $36(57.1)$ & $32(51.6)$ & - & $116(47.2)$ \\
\hline NYHA 3 & $13(21.3)$ & $25(39.7)$ & $29(46.8)$ & - & $67(27.2)$ \\
\hline NYHA 4 & - & $2(3.2)$ & $1(1.6)$ & - & $3(1.2)$ \\
\hline
\end{tabular}

NYHA: New York Heart Association, HF-rEF: Heart failure with reduced ejection fraction, HF-mrEF: Midrange heart failure, HF-pEF: Heart failure with protected ejection fraction

In the study, a moderate positive correlation $\left(R^{2}: 0.111\right.$, $P<0.001$ ) was found between NT-proBNP, which is an important biomarker for the diagnosis in HF-rEF and fetuin-A [Figure 1]. When HF-rEF and control group were compared, ROC analysis was performed to find the HF predictive value for fetuin-A, and cut-off 485 was determined ([area under curve (AUC): 0.74, sen: 0.72 [95\% confidence interval (CI): 0.57-0.82], spe: 0.69 [95\% CI: $0.59-0.83]$ ) and this determined value was found statistically significant [Figure 2 and $P<0.001$ ].

\section{Omentin-1}

While omentin-1 value [HF-rEF $22.9 \mathrm{ng} / \mathrm{mL}(16.8-29.7 \mathrm{ng} / \mathrm{mL})$, HF-mrEF $18.1 \mathrm{ng} / \mathrm{mL}(16.3-21.6 \mathrm{ng} / \mathrm{mL}), \mathrm{HF}-\mathrm{pEF} 18.1 \mathrm{ng} / \mathrm{mL}$ (16.5-22.8 ng/mL), control $19.3 \mathrm{ng} / \mathrm{mL}(16.9-22.7 \mathrm{ng} / \mathrm{mL})$, $P<0.001]$. HF-rEF was found to be significantly higher than the control group no significant difference was found between the other patient groups and the control group [Table 3]. Relatively low diagnostic performance was found in the ROC analysis performed to evaluate the diagnostic performance of Omentin-1 in the diagnosis of HF-rEF (AUC: 0.61, [0.51-0.72]).

\section{Chemerin}

Chemerin value (HF-rEF $6.42 \mathrm{ng} / \mathrm{mL}$ [6.16-8.53 ng/mL], HF-mrEF $6.16 \mathrm{ng} / \mathrm{mL}$ [5.91-6.36 ng/mL], HF-pEF6.3 ng/mL [5.9-8.6 ng/mL], control $6.2 \mathrm{ng} / \mathrm{mL}[5.9-6.4 \mathrm{ng} / \mathrm{mL}], P=0.003$ ) was found to be significantly low in HF-mrEF compared to HF-rEF group [Table 3]

\section{Discussion}

In this study, adiponectin levels such as fetuin-A, omentin-1, and chemerin in $\mathrm{HF}$ and their properties according to $\mathrm{HF}$ clinical classification were evaluated. To our knowledge, no study evaluating the clinical classification of $\mathrm{HF}$ and its adipokines has been conducted before. 


\begin{tabular}{|c|c|c|c|c|c|}
\hline Variables & HF-rEF $(n=61)$ & HF-mrEF $(n=63)$ & HF-pEF $(n=62)$ & Control $(n=60)$ & $P$ \\
\hline Hemoglobin (g/dL) & $13.99 \pm 1.53$ & $13.37 \pm 1.53$ & $13.46 \pm 1.20$ & $13.83 \pm 1.11$ & 0.053 \\
\hline Hematocrit (\%) & $42.28 \pm 4.61$ & $40.89 \pm 4.47$ & $41.26 \pm 3.97$ & $40.81 \pm 3.20$ & 0.178 \\
\hline Platelet $\left(10^{3} / \mathrm{u} / \mathrm{L}\right)$ & $212(169-240)$ & $216(181-275)$ & $212(172-264)$ & $242(208-283)$ & 0.343 \\
\hline $\operatorname{MCV}(f / L)$ & $88.31 \pm 5.19$ & $87.74 \pm 7.57$ & $85.62 \pm 7.48$ & $87.05 \pm 3.81$ & 0.096 \\
\hline $\operatorname{WBC}\left(10^{3} / \mathrm{u} / \mathrm{L}\right)$ & $8.42 \pm 2.25$ & $7.83 \pm 1.96$ & $7.75 \pm 1.81$ & $7.81 \pm 1.88$ & 0.208 \\
\hline Glucose (mg/dL) & $117(90-144)^{\mathrm{a}}$ & $112(89-130)^{\mathrm{a}}$ & $109(96-132)^{\mathrm{a}}$ & $95(90-112)^{b}$ & 0.008 \\
\hline Creatinine (mg/dL) & $1.19 \pm 0.36^{\mathrm{a}}$ & $1.13 \pm 0.51^{\mathrm{a}}$ & $1.27 \pm 0.57^{\mathrm{a}}$ & $0.83 \pm 0.18^{\mathrm{b}}$ & $<0.001$ \\
\hline BUN (mg/dL) & $28.04 \pm 14.29^{\mathrm{a}}$ & $27.83 \pm 13.46^{\mathrm{a}}$ & $33.34 \pm 15.10^{\mathrm{a}}$ & $15.96 \pm 5.41^{\mathrm{b}}$ & $<0.001$ \\
\hline Sodium $(\mathrm{mmol} / \mathrm{L})$ & $139.00 \pm 3.11$ & $139.38 \pm 4.00$ & $139.85 \pm 4.41$ & $141.28 \pm 6.12$ & 0.054 \\
\hline Potassium (mmol/L) & $4.58 \pm 0.61$ & $4.43 \pm 0.57$ & $4.44 \pm 0.66$ & $4.36 \pm 0.36$ & 0.220 \\
\hline CRP (mg/L) & $14.35 \pm 14.87^{\mathrm{a}}$ & $10.93 \pm 13.73^{\mathrm{a}, \mathrm{b}}$ & $17.49 \pm 22.15^{\mathrm{a}}$ & $6.00 \pm 6.44^{\mathrm{b}}$ & $<0.001$ \\
\hline Uric acid (mg/dL) & $7.38 \pm 2.61^{\mathrm{a}, \mathrm{b}}$ & $6.58 \pm 2.12^{\mathrm{a}}$ & $7.66 \pm 2.08^{b}$ & $5.14 \pm 1.34^{\mathrm{c}}$ & $<0.001$ \\
\hline $\operatorname{ALT}(\mathrm{U} / \mathrm{L})$ & $22.57 \pm 24.88$ & $38.71 \pm 88.08$ & $17.51 \pm 10.82$ & $25.81 \pm 16.64$ & 0.079 \\
\hline AST (U/L) & $24.06 \pm 17.95$ & $35.01 \pm 84.0$ & $21.20 \pm 10.46$ & $22.85 \pm 9.55$ & 0.287 \\
\hline GGT (U/L) & $67.78 \pm 62.52^{\mathrm{a}}$ & $60.55 \pm 53.79^{\mathrm{a}}$ & $51.85 \pm 52.97^{\mathrm{a}}$ & $36.73 \pm 30.56^{\mathrm{b}}$ & 0.007 \\
\hline TSH (ng/dL) & $2.52 \pm 4.89$ & $1.38 \pm 0.86$ & $2.10 \pm 4.20$ & $1.72 \pm 1.19$ & 0.254 \\
\hline $\mathrm{LDL}(\mathrm{mg} / \mathrm{dL})$ & $89.83 \pm 38.71^{\mathrm{a}}$ & $87.25 \pm 0.87^{\mathrm{a}}$ & $91.12 \pm 34.50^{\mathrm{a}}$ & $108.63 \pm 35.23^{\mathrm{b}}$ & 0.006 \\
\hline $\mathrm{TG}(\mathrm{mg} / \mathrm{dL})$ & $103(76-162)$ & $90(69-147)$ & $87(65-133)$ & $123(92-163)$ & 0.059 \\
\hline Cholesterol (mg/dL) & $154.95 \pm 53.64^{\mathrm{a}, \mathrm{b}}$ & $148.07 \pm 52.74^{\mathrm{a}}$ & $152.04 \pm 43.04^{\mathrm{a}}$ & $176.06 \pm 40.05^{\mathrm{b}}$ & 0.007 \\
\hline $\mathrm{EF}(\%)$ & $30(26-35)$ & $44(40-45)$ & $54(52-55)$ & $55(54-58)$ & $<0.01$ \\
\hline $\operatorname{EDC}(\mathrm{cm})$ & $5.84 \pm 0.82$ & $5.08 \pm 0.47$ & $4.70 \pm 0.34$ & $4.60 \pm 0.29$ & $<0.01$ \\
\hline LA size $(\mathrm{cm})$ & $4.5(4.1-4.8)$ & $4.4(4.2-4.7)$ & $4.5(4.2-4.8)$ & $3.6(3.4-3.8)$ & $<0.01$ \\
\hline Omentin-1 (ng/mL) & $22.9(16.8-29.7)^{\mathrm{a}}$ & $18.1(16.3-21.6)^{b}$ & $18.1(16.5-22.8)^{\mathrm{b}}$ & $19.3(16.9-22.7)^{\mathrm{b}}$ & $<0.001$ \\
\hline Chemerin $(\mathrm{ng} / \mathrm{mL})$ & $6.42(6.16-8.53)^{\mathrm{a}}$ & $6.16(5.91-6.36)^{b}$ & $6.3(5.9-8.6)^{\mathrm{a}, \mathrm{b}}$ & $6.2(5.9-6.4)^{\mathrm{a}, \mathrm{b}}$ & 0.003 \\
\hline Fetuin-A (ng/mL) & $555.3(453.7-615.6)^{\mathrm{a}}$ & $443.2(436.2-453.2)^{\mathrm{b}}$ & $512.7(452.6-571.6)^{\mathrm{a}}$ & $452.3(441.4-528.9)^{\mathrm{b}}$ & $<0.001$ \\
\hline NT-proBNP (ng/mL) & $31.3(29.1-43.3)^{\mathrm{a}}$ & $30.6(28.3-32)^{\mathrm{a}}$ & $29.2(25.5-29.6)^{b}$ & $5.3(3-11)^{c}$ & $<0.001$ \\
\hline
\end{tabular}

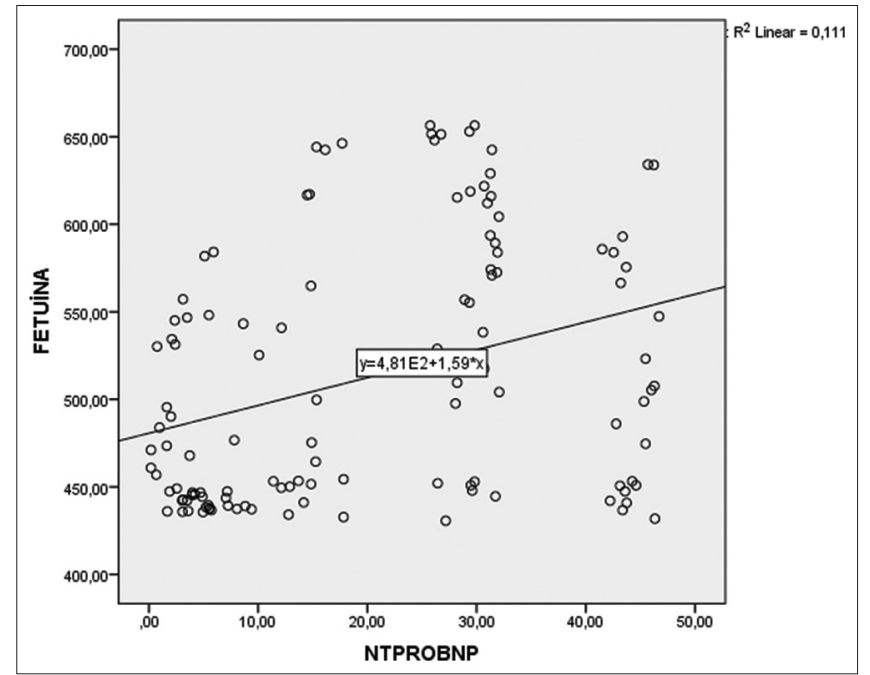

Figure 1: Correlation between fetuin-A and NT-proBNP

When the HF and the control group were compared, only fetuin-A among these adiponectins was found to be significantly higher than the control group. When the HF clinical groups were evaluated separately, it was found that fetuin-A was significantly higher in the HF-rEF and HF-pEF patient groups compared to the control group. Furthermore, a moderate positive correlation was found between fetuin-A and NT-proBNP, and it was shown that it could significantly detect HF-rEF with a cutoff value of 485 in the ROC statistic.

While the main assignment of adipose tissue is energy storage, this tissue also contains leukocytes, fibroblasts, macrophages, and connective tissue cells besides adipocytes. Adipose tissue can have both endocrine, paracrine, and autocrine effects through mediators called adipokines released from adipocytes and connective tissue cells between them. ${ }^{[14]}$ Although adipokines were first associated with obesity, consecutive studies have shown that these mediators also play a role in cardiovascular diseases..$^{[7]}$

Fetuin-A is a serum glycoprotein with a weight of approximately $60 \mathrm{KDa}$ discovered by Lebreton et al. toward the end of $1970 .{ }^{[15]}$ It has been found that fetuin-A, which is synthesized in the liver and then enters the blood circulation, plays a role in insulin resistance as well as being a calcification inhibitor. ${ }^{[16,17]}$ Due to the complex effects of adipokines on metabolism, different results were obtained in studies. ${ }^{[18]}$ For example, in a study conducted by Keçebaş et al. in which 66 HF-rEF and 31 healthy control groups were evaluated, they 


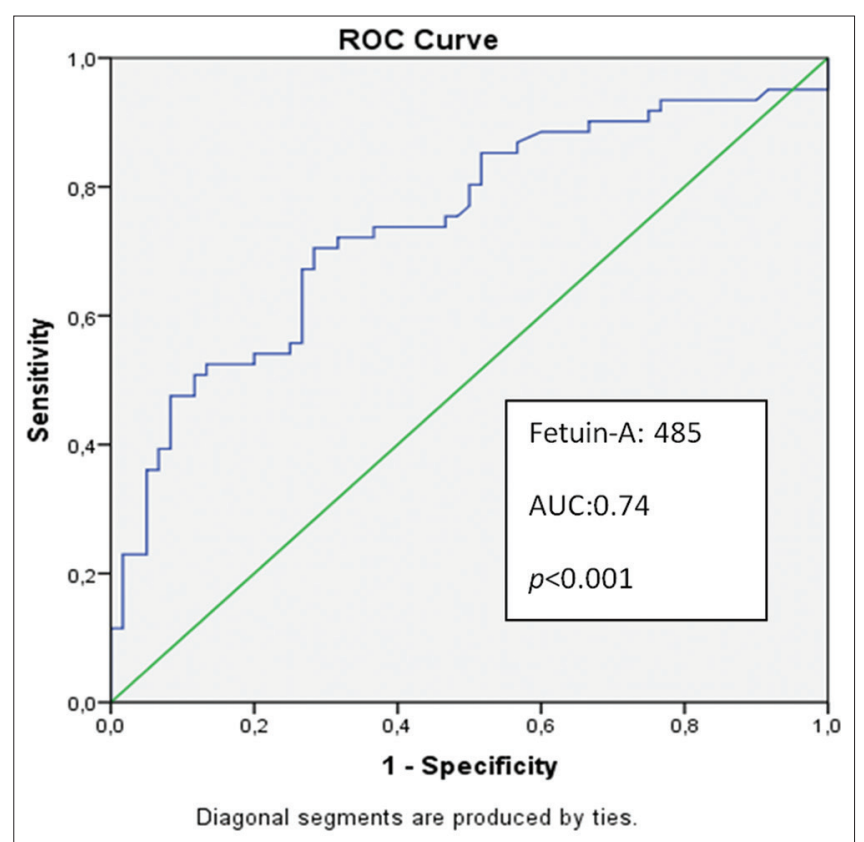

Figure 2: Receiver operating characteristic analysis to detect heart failure with reduced ejection fraction

found that serum fetuin-A levels decreased in patients with chronic HF-rEF. ${ }^{[19]}$ This study showed that the decrease in serum fetuin-A levels might be associated with cardiac diastolic dysfunction. In another study conducted by Joackim et al., it was found that high fetuin-A concentrations was strongly associated with metabolic syndrome and high LDL and low HDL concentrations. Thus, they found that high fetuin-A levels may be associated with CAD. ${ }^{[20]}$ Our study supports this study and serum fetuin-A levels were found to be high, especially in the HF-rEF patient group and we think that this may be due to the high rate of CAD accompanying this patient group at a rate of $85 \%$. At the same time, although CAD was higher in the HF-rEF group in our study, it did not differ compared to the control group. There are several studies showing that fetuin-A is associated with cardiovascular diseases by causing coronary artery and heart valve calcification. ${ }^{[21,22]}$ Furthermore, Weikert et al. found that high fetuin-A levels are associated with poor cardiovascular outcomes, including myocardial disease and ischemic stroke. ${ }^{[23]}$ In a study on 541 asymptomatic patients over 65 years of age were evaluated, the relation between fetuin-A levels and global cardiac functions in people with sarcopenia was evaluated. ${ }^{[24]}$ Sarcopenic LV dysfunction was defined as the coexistence of sarcopenia and systolic disorder (LVEF $<50 \%$ ) in the study. Serum fetuin-A levels were found to be significantly increased in 92 patients with sarcopenia compared to patients without sarcopenia. Fetuin-A levels were found to be similar regardless of systolic function in the group without sarcopenia. When multiple regression analysis was performed on these patients, age was found to be associated with impaired diastolic dysfunction and elevated fetuin-A levels. In conclusion, clinicians determined that patient age increases fetuin-A levels and impairs myocardial function, especially in patients with sarcopenia, and causes high end-diastolic pressure with HF. In our study, serum fetuin-A levels were found to be high, especially in HF-rEF with LV dysfunction. The patients' ages were above 65 years in all patient and control groups, and there was no significant difference between the patient and control groups. In addition, BMI was in favor of HF-rEF, although there was no statistically significant difference when the HF-rEF group and the control group were compared in terms of BMI. Therefore, our results were not affected by sarcopenia.

Measuring BNP levels in the blood, especially in the light of the data in the last 15 years, have made BNP a biomarker to be used to reveal patients with high ventricular filling pressure in HF. ${ }^{[25]}$ After BNP is secreted upon the stress caused by the filling pressure, firstly prepro-BNP and then NT-proBNP are formed by a series of reactions. ESC guidelines prepared for the diagnosis and treatment of chronic HF suggest that the measurement of the levels of these natriuretic peptides should be used as a clinical exclusion test. ${ }^{[26]}$ In a study conducted by Lichtenauer et al., 124 patients were evaluated. ${ }^{[10]}$ These patients were divided into two groups: 59 patients with ischemic and 65 patients with dilated cardiomyopathy. A positive correlation was found between fetuin-A and BNP in the subgroup of patients with dilated cardiomyopathy. BNP value increases in acute exacerbation of HF. For this purpose, NT-proBNP levels were measured in all individuals included in our study. In our study, a moderate positive correlation was found between NT-proBNP, ${ }^{[27]}$ which has been validated for HF and provides invaluable information on prognosis, and fetuin-A $(P<0.001)$.

EPIC Potsdam was a case - control study with an 8-year follow-up in 27548 patients. In the subgroups of this study, the patient groups with a total of 212 patients with HF and 2168 patients without HF were compared ${ }^{[1]}$ At the end of the study, there was no significant association between omentin-1 and HF. However, a relationship was found between high plasma omentin-1 levels and cardiovascular diseases in the subgroups of this study evaluated for myocardial infarction. As a result of this, the researchers defended the thesis that the relationship between omentin-1 and HF changes with respect to a previous CAD. In our study, when all HF groups and the control group were compared, no significant difference was found in omentin-1, but a significant difference was observed in HF-rEF patients with accompanying more CAD in our study population $(P<0.001)$. In another study, 189 patients with $\mathrm{HF}$; were divided into two groups as $\mathrm{EF}>40$ (111 patients) and $\mathrm{EF}<40$ (78 patients). ${ }^{[28]}$ In the subsequent evaluation, the investigators found significantly higher serum omentin-1 levels in patients with $E F<40$. In conclusion, they suggested that the elevation of serum omentin-1 levels was slightly associated with changes in heart volume and function in patients with HF. Our study supports this study and omentin-1 levels were found to be increased in the HF-rEF group. There was no significant difference between the other HF groups and the control group. However, large-scale randomized controlled studies are needed to use omentin- 1 in the development process and pathogenesis of HF. 
Chemerin is an adipokine produced from the liver and adipose tissue. ${ }^{[29]}$ In a study, it was found that chemerin concentrations were associated with CAD and the severity of coronary atherosclerosis. ${ }^{[30]}$ In the study conducted by Xiaotao et al., 188 patients were evaluated and coronary angiography was performed in all patients. Patients with more than $50 \%$ stenosis in their coronary vessels on coronary angiography were considered to have CAD. Thus, 132 patients were evaluated as $\mathrm{CAD}$ and 56 patients as the control group. However, patients with HF, myocarditis, pericarditis, CABG, patients who underwent PCI, and patients with lipid-regulating medication were excluded from the study. As a result of the study, serum chemerin levels were found to be significantly higher in CAD patients compared to those without CAD. In our study, the frequency of CAD was found to be increased in the HF-rEF and HF-mrEF groups, and it was not found to be significantly higher than the control group. We did not find a significant difference in chemerin levels in these patients. In the EPIC Potsdam study, which is a large-scale study, the risk of developing HF with plasma chemerin concentration was also investigated. ${ }^{[11]}$ The hypothesis of the study contained also to determine whether chemerin doses in CAD are associated with HF or not. As a result of this study, chemerin was found to be strongly associated with the risk of HF, and the risk of HF was found to be significantly higher at doubled chemerin concentrations. Furthermore, in a study performed by $\mathrm{Ou}$ Zhang, Qingwei Ji et al., plasma chemerin concentrations were found to be significantly higher in patients with dilated cardiomyopathy compared to the control group ${ }^{[31]} \mathrm{A}$ total of 109 patients were included in the evaluation, and patients with normal coronary arteries in coronary angiography were included in the study. For all evaluated patients their $\mathrm{EF}<50 \%$ and all their LV diastolic diameters were above $55 \mathrm{~mm}$. At the same time, 25 patients in functional class II, 47 patients in class III and 37 patients in class IV according to NYHA standards were included in the study, but patients with NYHA Class I were not included in the study. In our study, we did not observe a significant difference in chemerin levels between any HF group and the control group, we thought that this might be due to the patients not being under serious volume burden. However, more randomized controlled studies are needed for the use of chemerin in HF. However, more randomized controlled studies are needed for the use of chemerin in HF.

\section{Conclusion}

In our study, fetuin-A was found significantly higher in HF-rEF and HF-pEF patient groups compared to the control group. In addition, a moderately significant positive correlation was found between fetuin-A and NT-proBNP, and it was able to significantly detect HF-rEF in the ROC curve. Omentin-1 and chemerin could not predict the HF groups with sufficient sensitivity and specificity. We think that among adipokines, fetuin-A is the best predictor for HF, this predictability is due to the HFrEF group. Clinical use of fetuin-A may be possible with the confirmation of these results in large-scale studies.

\section{Limitations of the study}

The relatively small number of patients in our study is one of the limitations, and it is unknown whether the patients are sarcopenic or not. The fact that statistically different gender distribution and mean age between patient groups and control groups may have affected adiponectin levels. The control group and the HF-rEF group are not equivalent in terms of CAD. The volume status of the patients may differ from each other, and we do not know if this affected our results. After the patients were included in the study, we could not determine whether their adiponectin levels were affected by the changes in the clinical condition of the same patients, as we did not have follow-up data.

\section{Acknowledgments}

I would like to thank my family, my colleagues, and the entire scientific community.

\section{Financial support and sponsorship}

Nil.

\section{Conflicts of interest}

There are no conflicts of interest.

\section{REFERENCES}

1. Braunwald E. The denolin lecture. Congestive heart failure: A half century perspective. Eur Heart J 2001;22:825-36.

2. Bui AL, Horwich TB, Fonarow GC. Epidemiology and risk profile of heart failure. Nat Rev Cardiol 2011;8:30-41.

3. Cowie MR, Wood DA, Coats AJ, Thompson SG, Suresh V, Poole-Wilson PA, et al. Survival of patients with a new diagnosis of heart failure: A population based study. Heart 2000;83:505-10.

4. Ma H, Liu J, Qian L. Fat for fostering: Regenerating injured heart using local adipose tissue. EBioMedicine 2016;7:25-6.

5. Ferroni P, Basili S, Falco A, Davì G. Inflammation, insulin resistance, and obesity. Curr Atheroscler Rep 2004;6:424-31.

6. Wang Z, Nakayama T. Inflammation, a link between obesity and cardiovascular disease. Mediators Inflamm 2010;2010:535918.

7. Jung UJ, Choi MS. Obesity and its metabolic complications: The role of adipokines and the relationship between obesity, inflammation, insulin resistance, dyslipidemia and nonalcoholic fatty liver disease. Int $\mathrm{J}$ Mol Sci 2014;15:6184-223.

8. Sánchez-Recalde A, Kaski JC. Diabetes mellitus, inflammation and coronary atherosclerosis: Current and future perspectives. Rev Esp Cardiol 2001;54:751-63

9. Cousin B, Munoz O, Andre M, Fontanilles AM, Dani C, Cousin JL, et al. A role for preadipocytes as macrophage-like cells. FASEB J 1999; 13:305-12.

10. Lichtenauer M, Wernly B, Paar V, Rohm I, Jung C, Yilmaz A, et al. Specifics of fetuin-A levels in distinct types of chronic heart failure. J Clin Lab Anal 2018;32: e22179.

11. Menzel J, Giuseppe R, Biemann R, Wittenbecher C, Aleksandrova K, Eichelmann F, et al. Association between chemerin, omentin-1 and risk of heart failure in the population-based EPIC-Potsdam study. Sci Rep 2017;7:14171.

12. Lang RM, Bierig M, Devereux RB, Flachskampf FA, Foster E, Pellikka PA, et al. Recommendations for chamber quantification: A report from the American Society of Echocardiography's Guidelines and Standards Committee and the Chamber Quantification Writing Group, developed in conjunction with the European Association of Echocardiography, a branch of the European Society of Cardiology. J Am Soc Echocardiogr 2005;18:1440-63.

13. Ponikowski P, Voors AA, Anker SD, Bueno H, Cleland JG, Coats AJ, et al. 2016 ESC Guidelines for the diagnosis and treatment of acute 
and chronic heart failure: The task force for the diagnosis and treatment of acute and chronic heart failure of the European Society of Cardiology (ESC). Developed with the special contribution of the Heart Failure Association (HFA) of the ESC. Eur J Heart Fail 2016;18:891-975.

14. Tilg H, Hotamisligil GS. Nonalcoholic fatty liver disease: Cytokine-adipokine interplay and regulation of insulin resistance. Gastroenterology 2006;131:934-45.

15. Lebreton JP, Joisel F, Raoult JP, Lannuzel B, Rogez JP, Humbert G. Serum concentration of human alpha 2 HS glycoprotein during the inflammatory process: Evidence that alpha 2 HS glycoprotein is a negative acute-phase reactant. J Clin Invest 1979;64:1118-29.

16. Jiang Q, Dibra F, Lee MD, Oldenburg R, Uitto J. Overexpression of fetuin-A counteracts ectopic mineralization in a mouse model of pseudoxanthoma elasticum (abcc6(-/-)). J Invest Dermatol 2010;130:1288-96.

17. Ou HY, Wu HT, Hung HC, Yang YC, Wu JS, Chang CJ. Endoplasmic reticulum stress induces the expression of fetuin-A to develop insulin resistance. Endocrinology 2012;153:2974-84.

18. Mehta S, Farmer JA. Obesity and inflammation: A new look at an old problem. Curr Atheroscler Rep 2007;9:134-8.

19. Keçebaş M, Güllülü S, Sağ S, Beşli F, Açikgöz E, Sarandöl E, et al. Serum fetuin-A levels in patients with systolic heart failure. Acta Cardiol 2014;69:399-405.

20. Ix JH, Shlipak MG, Brandenburg VM, Ali S, Ketteler M, Whooley MA. Association between human fetuin-A and the metabolic syndrome: Data from the Heart and Soul Study. Circulation 2006;113:1760-7.

21. Merx MW, Schäfer C, Westenfeld R, Brandenburg V, Hidajat S, Weber $\mathrm{C}$, et al. Myocardial stiffness, cardiac remodeling, and diastolic dysfunction in calcification-prone fetuin-A-deficient mice. J Am Soc Nephrol 2005;16:3357-64.

22. Lim P, Moutereau S, Simon T, Gallet R, Probst V, Ferrieres J, et al. Usefulness of fetuin-A and C-reactive protein concentrations for prediction of outcome in acute coronary syndromes (from the French
Registry of Acute ST-Elevation Non-ST-Elevation Myocardial Infarction [FAST-MI]). Am J Cardiol 2013;111:31-7.

23. Weikert C, Stefan N, Schulze MB, Pischon T, Berger K, Joost HG, et al. Plasma fetuin-a levels and the risk of myocardial infarction and ischemic stroke. Circulation 2008;118:2555-62.

24. Chang WT, Tsai WC, Wu CH, Lee YW, Tai YL, Li YH, et al. Fetuin-A as a predicator of sarcopenic left ventricular dysfunction. Sci Rep 2015;5:12078

25. Francis GS, Benedict C, Johnstone DE, Kirlin PC, Nicklas J, Liang CS, et al. Comparison of neuroendocrine activation in patients with left ventricular dysfunction with and without congestive heart failure. A substudy of the studies of left ventricular dysfunction (SOLVD). Circulation 1990;82:1724-9.

26. Remme WJ, Swedberg K; Task Force for the Diagnosis and Treatment of Chronic Heart Failure; European Society of Cardiology. Guidelines for the diagnosis and treatment of chronic heart failure. Eur Heart J 2001;22:1527-60.

27. Januzzi JL, van Kimmenade R, Lainchbury J, Bayes-Genis A, Ordonez-Llanos J, Santalo-Bel M, et al. NT-proBNP testing for diagnosis and short-term prognosis in acute destabilized heart failure: An international pooled analysis of 1256 patients: The International Collaborative of NT-proBNP Study. Eur Heart J 2006;27:330-7.

28. Jiang H, Zhao G, Li X, Jin H, Yang G, Jin K, et al. Association between omentin and echo parameters in patients with chronic heart failure. Minerva Cardioangiol 2017;65:8-15.

29. Rodríguez-Penas D, Feijóo-Bandín S, García-Rúa V, Mosquera-Leal A, Durán D, Varela A, et al. The adipokine chemerin induces apoptosis in cardiomyocytes. Cell Physiol Biochem 2015;37:176-92.

30. Xiaotao L, Xiaoxia Z, Yue X, Liye W. Serum chemerin levels are associated with the presence and extent of coronary artery disease. Coron Artery Dis 2012;23:412-6.

31. Zhang O, Ji Q, Lin Y, Wang Z, Huang Y, Lu W, et al. Circulating chemerin levels elevated in dilated cardiomyopathy patients with overt heart failure. Clin Chim Acta 2015;448:27-32. 